\title{
The relationship between alexithymia and career decision - making self-efficacy among Tenth and Eleventh - grade students in Muscat Governorate
}

\author{
Mohammad Sheikh Hammoud $\left.{ }^{\star *}\right)$, Bakkar S. Bakkar², Yousef Abdulqader Abu Shendi, \\ Yousuf saif Al Rujaibi ${ }^{4}$ \\ ${ }^{123}$ Psychology Department, College of Education, Sultan Qaboos University, Oman \\ ${ }^{4}$ Ministry of Education, Oman \\ ${ }^{*}$ Corresponding author, Đe-mail: drhammoud@squ.edu.om
}

\begin{abstract}
The purpose of this study was to examine the relationship between alexithymia and career decision -making self-efficacy among Tenth and Eleventh- grade students in Muscat Governorate. Alexithymia Scale (AS), and CDMSE Short Form were administered to a total sample of 556 students of Tenth and Eleventh grades $(n=278)$ males and $(n=278)$ females. Findings revealed that the level of alexithymia was less than the mean of items, while the level of CDMSE was more than the mean of items, as well as there was no significant correlational relationship between alexithymia and CDMSE. The results also revealed that there were significant gender differences in alexithymia, while there were no significant gender differences in CDMSE. With regard to GPA, the findings revealed that there were no significant differences in alexithymia, while there were significant differences in CDMSE. Conclusion: It concludes that although there was no significant correlational relationship between alexithymia and career decision-making self-efficacy, alexithymia negatively affects individuals' decision -making in their own lives.
\end{abstract}

Keywords: Alexithymia, career decision -making self-efficacy, Tenth and Eleventh grades

How to Cite: Hammoud, M. S., Bakkar, B. S., Shendi, Y. A. A., \& Al Rujaibi, Y. S. (2019). Relationship between alexithymia and career decision-making self-efficacy among Tenth and Eleventh grade students in Muscat governorate. COUNS-EDU: The International Journal of Counseling and Education, 4(2): pp. 45-59. DOI: https://doi.org/10.23916/0020190420520

\section{Introduction}

Alexithymia is one of the psychological concepts that deserves in-depth research; because it reflects the extent to which the individual deals with kinds of feeling in different situations. In general, Alexithymia refers to a disruption in both emotional and cognitive processes such that the person has trouble recognizing his or her own emotions and has a reduced emotional and fantasy life so that he or she seems concerned only with details of everyday life without a sense of direction or purpose (Matsumoto, 2009, p. 28).

Alexithymia, a term coined by Sifneos (1972) (from the Greek: a = lack, lexis = word, thymos = emotion), refers to a specific disturbance in psychic functioning characterized by difficulties in the capacity to verbalize affect and to elaborate fantasies (Taylor, 1984, P.81). Because psychoanalysts and psychotherapists rely on affects and fantasies to gain access to their patients' intrapsychic lives, alexithymic individuals are typically poor candidates for insight-oriented psychotherapies. Patients with reduced 
emotional expressiveness and a limited fantasizing ability were described by psychotherapists long before the alexithymia concept was introduced and were referred to like people who are not psychologically minded (Taylor, 1987). Although initially described in the context of psychosomatic illness, alexithymic characteristics may be observed in patients with a wide range of medical and psychiatric disorders (Taylor, 1984).

The clinical construct of alexithymia defines more precisely the phenomenological characteristics of these difficult patients and has led to several hypotheses and to numerous empirical studies that are beginning to shed light on the nature of their cognitive affective disturbance. Sociocultural factors must also be considered when evaluating the alexithymia construct (Taylor, 1987).

According to Taylor (2000), the core features of alexithymia include difficulty identifying feelings and distinguishing them from bodily sensations of emotional arousal, difficulty describing feelings to other people, and an externally oriented cognitive style.

Alexithymia is a trait characterized by "(1). Difficulty identifying feelings and distinguishing between feelings and bodily sensations of emotional arousal; (2). Difficulty describing feelings to other people; (3). Constricted imaginal process, as evidenced by a paucity of fantasies; and (4) a stimulus-bound, externally oriented cognitive style" (Taylor, Bagby, \& Parker, 1997, p. 29). Accordingly, the characteristics mentioned above can summarized into five salient features as follows: (I). A reduction or incapacity to experience emotions, (II). A reduction or incapacity to verbalize emotions; (III). A reduction or incapacity to fantasize; (IV). An absence of tendencies to think about one's emotions; and (V). Difficulty in identifying emotions (Hendryx, Haviland and Shaw, 1991, Taylor, Ryan, and Bagby, 1985).

Alexithymia is characterized by an impoverished fantasy life and limited imagination, an impaired capacity for empathy, a propensity for impulsive behavior, a tendency to somatize emotions, and a penchant for offering undifferentiated descriptions of emotional experience (Warnes, 1986; Taylor, 2000).

Alexithymic individuals often have constricted imaginations and fantasies, are preoccupied with objects and events in the outside world, and have a limited private, personal internal life. When distressed, these patients are simply aware of not feeling well and usually complain of somatic symptoms, leading to frustrating interactions with their physicians who are unable to find physical causes for the presenting physical complaints. Some view alexithymia as a condition in which affect is communicated through somatic language (Sadock and Sadock, 2000).

Alexithymia is a risk factor for a variety of psychological problems and disorders such as depression, anxiety, and substance use disorders (Honkalampi, Kintikka, Tanskanen, Lehtonen, Viinamaki, 2000; Taylor et al., 1997; Taylor, Parker, Bagby, \& Bourke, 1996; Zackheim, 2007). Additionally, research indicates that alexithymia may develop because of early life traumatic experiences and stress (Honkalampi et al., 2004; Lumley, Neely, \& Burger, 2007; De Vente, Kamphuis, \& Emmelkamp, 2006).

The concept of alexithymia evolved from clinical observations that were initially made on patients with classical psychosomatic diseases. For many years, the psychic disturbance in these patients was conceptualized according to Freud's model of neurotic pathology, and professionals in psychosomatic medicine attempted to relieve somatic symptoms by identifying and interpreting unconscious emotional conflicts. However, some of the early leaders in psychosomatic medicine believed that psychosomatic diseases could not be explained by analogy with the neuroses; they reported observations, which suggested that it is a disturbance of emotional expressiveness that predisposes people to psychosomatic illnesses (Taylor, 1987).

Other psychological constructs seem similar to alexithymia and may be confused with it. Some constructs represent emotional skills, abilities, or strengths, rather than deficits or limitations. For example, emotion regulation is broader than alexithymia and refers to a wide range of processes, including being aware of emotions, accessing and expressing emotions, and monitoring and controlling emotions (Dahl, 2003).

Emotion regulation is so broad that it is difficult to define, and there are no assessment devices that capture the full range of emotion regulation processes. Emotional intelligence also is broader than alexithymia, and the leading theorists propose four characteristics: perceiving emotions in others, using 
emotions to facilitate thought, understanding emotions, and managing emotions (Mayer, Salovey, Caruso, \& Sitarenios, 2001). Whereas alexithymia refers to basic emotion processes, emotional intelligence refers more to the application or implications of such basic emotional abilities.

Psychometrically, Vorst and Bermond (2001) developed the Bermond-Vorst Alexithymia Questionnaire (BVAQ), which builds on Nemiah and Sifneos's original definition, and conceptualizes the construct as having the following five measurable traits: (1) Verbalizing emotions (i.e., ability to verbally communicate emotions), (2) Identifying emotions (i.e., ability to identify and differentiate between emotions, (3) Fantasizing (i.e., ability to fantasize, imagine, or daydream), (4) Analyzing emotions (i.e., the tendency or capacity to reflect upon and attempt to explain one's emotions), and (5) Emotionalizing (i.e., ability to experience emotions).

Self-efficacy is the concept, which was firstly coined by Bandura. Bandura's self-efficacy theory is grounded in Social Cognitive Theory (2001). Self-efficacy theory provides explicit guidelines on how to develop and enhance human efficacy. According to this theory, People make causal contributions to their own psychosocial functioning through mechanisms of personal agency. Among the mechanisms of agency, none is more central or pervasive than people's beliefs of personal efficacy (Bandura, 2009).

Bandura defined self-efficacy as perception and belief in one's abilities. He ascertained that one's perception of abilities and human agency shape one's endeavors to achieve. Self-efficacy contains many dimensions and is dependent on the person's cognitions (Bandura, 1982).

Perceived self-efficacy refers to beliefs in one's capabilities to organize and execute the courses of action required to manage prospective situations. Efficacy beliefs influence how people think, feel, motivate themselves, and act. A central question in any theory of cognitive regulation of motivation, affect, and action concerns the issues of causality. Efficacy beliefs regulate human functioning through four major processes. They include cognitive, motivational, affective, and selection processes. These different processes usually operate in concert, rather than in isolation, in the ongoing regulation of human functioning (Bandura, 2009).

Self-efficacy is an individual's perceived ability to successfully accomplish established goals. Perceived self-efficacy is a belief that a person can organize and execute the actions necessary to produce particular outcomes. Efficacy beliefs are instrumental in the activities and situations and the direction of personal development (Bandura, 1977).

Perceived self-efficacy also involves self-appraisal and it involves more than simply knowing what to do. Regarding sources of self-efficacy beliefs, four types of influence contribute to individuals' beliefs about their self-efficacy. They are mastery experiences, vicarious experiences, social persuasion, and physiological emotional states (Bandura, 2009).

Self-efficacy theory posits the causal role of efficacy judgments in the development of vocational interests (Bandura, 1986). Occupational self-efficacy and interests have consistently been found to be moderately related. Theoretically, strong career efficacy beliefs should give rise to enhanced occupational interests (Lent, Brown, \& Hackett, 1994). Overall, it appears that career self-efficacy is strongly predictive of a wide range of career-related behaviors from early high school through college and beyond (Hackett \& Lent, 1992; Lent \& Hackett, 1987).

Taylor and Betz (1983) developed the Career Decision Making Self-efficacy (CDMSE) Scale to assess perceptions of efficacy with regard to these five dimensions of career decision making. One assumption guiding this research has been that effective career decision making involves not only the development of skills but also confidence in one's decision-making abilities. They hypothesized that weak decision making self-efficacy could impede career exploratory behavior and the development of decision making skills, and thus may be predictive of career indecision and other problems in career decision making. According to Taylor and Betz (1983), Career decision-making self-efficacy is "an individual's belief that he or she can engage in activities such as accurate self-appraisal, gathering of relevant occupational information, and selecting appropriate goals". As alexithymia is as disruption in both emotional and cognitive processes, and this disruption may result in weak sense or loss of sense of direction or purpose; diminished ability to think or concentrate, or indecisiveness may occur. The ability to make crucial career decisions may be influenced by this disruption. The contention of this logic relationship may be found in Cecchetto, Korb, Ida Rumiati, and Aiello (2017) who investigated the

The relationship between alexithymia and career decision -making self-efficacy among Tenth and Eleventh ... 47 Indonesian Counselor Association (IKI) | DOI: https://doi.org/10.23916/0020190420520 
influence of empathy and alexithymia on behavior and emotional responses while participants performed a moral decision task. Results showed that empathy and alexithymia shaped emotional reactions to moral decisions, but did not bias moral choices. These results add new evidence to the field of moral decision showing that empathy and alexithymia modulate emotional reactions to moral decision. Consequently, Self-efficacy can be strengthened by learning experiences, which include "personal performance accomplishments, observational learning (or modeling), social encouragement and persuasion, and physiological and affective states and reactions" (Lent \& Brown, 2013a \& 2013b).

Literature included studies conducted to assess alexithymia in children and adolescents, but research into alexithymia and adolescence is extremely limited with the vast majority of studies focusing on alexithymia in adults and patients in clinical and psychiatric settings. Of the studies that have been conducted, considerable support has been found suggesting that adolescent alexithymia is associated with many of the same mental health concerns as found in the adult literature (Easterbrook, 2007). In addition, the literature also included research studies on examining career making decision self-efficacy (CMDSE) in diverse categories of people in different developmental stages. More generally, however, relationship between alexithymia and career making decision self-efficacy (CMDSE) did not receive any interest among researchers, so there are not studies conducted and well documented in this context. This relatively different interest may be due to that the concept of alexithymia is often studied within the context of psychiatry and mental health, while the career making decision self-efficacy is often studied within the context counseling, specifically career counseling. As alexithymia psychiatric concept, the researchers attempt to study it by investigating its relationship with other psychiatric and psychotherapeutic concepts and variables, and they find difficulty to create a rationale to study this concept with other educational and psychological concepts like problem solving and decision making. Consequently, we were very enthusiastic and keen on doing this research to connect psychiatric settings with educational and psychological ones, so this gave the current study great importance and originality to explore the nature of the relationship between alexithymia and CMDSE. Eastabrook (2007) conducted a study to examine TAS20 among 310 clinical adolescents (mean age $=15.3$ years) and 705 community-based adolescents (mean age $=16.3$ years). Confirmatory factor analytic results provided good empirical support for use of the TAS20 in older community-based adolescents. Results from confirmatory factor analyses indicated that female adolescents tended to have greater difficulty identifying feelings than the males. Male adolescents were found to score significantly higher than the females on externally oriented thinking and total TAS-A.

Loas, Braun, Delhaye, and Linkowski, (2017) measured alexithymia in children and adolescents. Four groups were examined ( 80 healthy children, 105 adolescents with various psychiatric disorders, 333 healthy older adolescents and 505 young adults recruited from universities) by administering Alexithymia Questionnaire for Children (AQC) and the latter two the 20-item Toronto Alexithymia Scale (TAS-20). Findings from this study revealed that alexithymia can be reliably assessed in adolescents using the TAS20 or AQC, as well as children or adolescents were able to discriminate alexithymia from depression which means that TAS-20 can explore alexithymia in children and adolescents reliably.

Kaur and kaur (2015) conducted a study to investigate the relationship of social anxiety with alexithymia among adolescents. A total of 210 students (105 males, 105 females) from different school of Patiala, Punjab were assessed using Social Anxiety Scale for Adolescents (SAS-A) and Rieffe's Children's Alexithymia Scale. It was found that social anxiety was positively related to alexithymia and female adolescents were higher in social anxiety as compared to male adolescents. Significant gender differences were obtained on only one aspect of alexithymia; that is females were higher than males. Gender difference was not significant on other alexithymia dimensions.

The relation of alexithymia (cognitive and affective deficit in processing, adjustment and verbalizing emotions) with interpersonal problems was explored in (174) high-school students who completed Toronto Alexithymia Scale (TAS-20). Alexithymia was positively correlated with interpersonal problems, high alexitymic adolescents had significantly more interpersonal problems than non alexithymic adolescents. (Puşcaşua, and Usaci, 2016). These findings may go along with those ones revealed by Cerutti, Valastro, Tarantino, Valeriani, Faedda, Spensieri and Guidetti (2016) in their research to explore the relationship between alexithymia and psychosomatic disorders denoted by psychopathological symptoms among 212 adolescents and mothers with migraines who completed the Toronto Alexithymia Scale Findings revealed that factor analysis has consistently yielded three factors that assess the salient features of the alexithymia construct: difficulty identifying feelings, difficulty describing feelings, and externally-oriented thinking. 
Furthermore, adolescents and mothers experiencing both migraine and alexithymia demonstrated a higher risk of psychopathology. It seems that these findings demonstrated what were indicated in the study of Sakkinen, Kaltiala-Heino, Ranta, Haataja, \& Joukamaa (2007) to assess alexithymia in a sample of 12 to 17 -year-old adolescents, and found the prevalence of alexithymia in $15.9 \%$ in all participants, $14.6 \%$ in males and $17.3 \%$ in females, but the gender difference was not statistically significant. These findings were consistent with the results of study conducted by Honkalampi, Tolmunen, Hintikka, Rissanen, Kylma, Laukkanen (2009) and attempted to assess alexithymia among a sample of 13 to 18-year-old adolescents at $7.3 \%$ with $4.9 \%$ in males and $9.4 \%$ in females. The findings revealed that prevalence was higher in females in all age groups but no significant gender difference in alexithymia was observed in this study.

In regard to career making decision self-efficacy, there were relatively considerable studies in literature. These studied varied in target samples and other variables to which this concept correlates. Ziebell (2010) conducted a study to predict the role of person factors, environmental factors, and career maturity in career decision-making self-efficacy in 10th through 12th grade adolescents. Findings indicated that students reported greater levels of career decision-making self-efficacy, as well as career decisionmaking self-efficacy and vocational outcome expectations were positively related to career choice goals. No significant gender differences were found in career decision-making self-efficacy. These findings are inconsistent with the findings of study conducted by Yat Hung (2007) studying career decision-making self-efficacy in 1216 students from 14 secondary schools in Hong Kong, that is these findings revealed that gender had significant impact on career decision-making self-efficacy scores. This result was proved by Wan Lai Yin (2013) who conducted a study to investigate roles of parental influences, personality and career decision-making self-efficacy in predicting vocational interests and choice goals among Hong Kong secondary school students. Findings from this study revealed that there were significant gender differences in interests, self-efficacy, gender role attitudes, and gender-typicality in aspiration-expectation incongruence. The same results were subsequently maintained by Lozano (2015) whose study findings indicated increased positive significant differences in the inner resources, interpersonal strengths, and work habits subscales on the achievement motivation profile and significant gender differences positively increased for females in the Planning subscale of the career decision self-efficacy scale.

Although in a number of researchers have found no significant differences between males and females on measures of career decision-making self-efficacy (Bergeron \& Romano, 1994; Bright, 1996; Wilson, 2000), gender differences have been found in career decision-making self-efficacy for nontraditional careers. For instance, Betz and Hackett (1986) found that females report higher efficacy expectations and outcome expectations for traditionally female occupations than for traditionally male occupations.

It seems as mentioned above that most studies related to alexithymia were conducted with individuals in medical, psychiatric and clinical settings, but there has been little research conducted on normal populations in schools or other educational settings. These studies attempted to examine gender differences in alexithymia, some of them showed that gender differences exist, but others showed no gender differences. With regard to career making decision self-efficacy, there have been studies conducted on examining CMDSE in high school students to show gender differences and its CMDSE relationship to other variables. Unfortunately, there has not been research conducted to examine the relationship between alexithymia and CMDSE. Because alexithymic people have externally oriented thinking, it is postulated that their decision-making will be influenced by external factors, and not attributed to internality.

\section{Problem statement and objective}

Alexithymia is difficulty identifying and describing feeling as well as making thinking externally oriented. These features motivate researchers to explore life dimensions and situations that can be influenced positively or negatively by alexithymia. One of these situations for individual is how to make crucial decisions in different life circumstances. Specifically, the authors attempted to examine the relationship of alexithymia and career making decision self -efficacy. It was hypothesized that externally oriented thinking in alexithymic students will negatively affect their career decision making. This study aimed at examining the relationship between alexithymia and CMDSE among Tenth and Eleventh grade students in Muscat Governorate. 


\section{Problem questions}

This study attempted to answer the following questions: 1) What is the degree of alexithymia and career decision making self-efficacy (CDMSE) among Tenth and Eleventh grade students? 2) Is there a significant correlational relationship between alexithymia and career decision making self-efficacy (CDMSE)? 3) Are there significant effects in alexithymia due to gender, and GPA? 4) Are there significant effects in career decision-making self-efficacy (CDMSE) due to gender, and GPA?

\section{Significance of study}

The importance of this study emerges from that the relationship between alexithymia and career decision making self-efficacy was not previously studied in the literature; because alexithymia was exclusively investigated in most research studies in psychiatric and medical settings as a psychological problem or disorder. Since the subject of alexithymia research studies are classified within the field of psychiatry and psychosomatics; variables whose relationships with alexithymia were studied were psychiatric or psychosomatic ones, such as: depression, migraine, anxiety or substance abuse, but variables related to other life experiences such as academic achievement, or career decision making were not investigated in the context of alexithymia. This study sheds light on examining the relationship between alexithymia and career decision -making self-efficacy among Tenth and Eleventh grade students. This gives it distinction in career counseling in terms of connecting counseling variables with psychological and psychiatric variables. This study is also very important culturally for European and Arab populations; because some minorities which live in Europe descend from Arab and Muslim origins on one hand, some European people work in Arab Gulf states on the other hand, so the Europeans need to understand these minorities and deal with them, which means that it is essential for them to perceive and understand the nature of expressing feelings and making decisions in the Arab context.

\section{Method}

\section{Population and Sample}

The population of this study consisted of 15350 sophomore and junior students of four public high schools in Muscat Directorate of education in Sultanate of Oman. A random cluster sample of 556 students was selected from the target population with percentage of 3.6\%. Of the total size of the sample $50 \%$ were males $(n=278)$ and $50 \%$ were females $(n=278)$ representing the Tenth grade $(n=281) 51 \%$, and the Eleventh grade $(\mathrm{n}=275) 49 \%$, their age ranged from $15-17$ years old with average of 16.1 years.

\section{Instrumentation}

Alexithymia Scale (AS) was developed based on the 20-item Toronto Alexithymia Scale (TAS-20) (Bagby, Parker, \& Taylor, 1994) to assess the degree to which individual has Alexithymia. The SA in its primary version was composed of 35 items which measure three subscales: Difficulties identifying feelings and distinguishing them from bodily sensations (DIF), 2) Difficulties describing feelings (DDF), and 3) Externally-oriented thinking (EOT).

\section{Validity}

Face validity was assessed by submitting the scale to a panel of experts whose specialization is counseling or psychological measurement. Construct validity was also assessed by conducting Exploratory Factor Analysis on a pilot sample $(n=60)$. Factor Analysis yielded one factor with 28 items; that is, 7 items were deleted because of low loadings, figure 1. Consequently, the final version of the AS items included 28 items, which are responded according to a 5-point Likert-type scale: (extremely $=5$, very $=4$, moderately $=3$, slightly $=2$ and not at all $=1$ ). The total score (maximum score) obtained by summing up the scores of all items was 140 , the minimum score was 28 , and the average score was 84 . Any score above 84 indicates higher degree of Alexithymia and any score at 84 indicates moderate Alexithymia, while any score below 84 indicates lower degree of Alexithymia.

\section{Reliability}

Reliability was expressed by Cronbach Alpha to find internal consistency for all items. The AS has demonstrated solid internal consistency (Cronbach's alpha $=0.91$ ). as shown in table 1 . 
Table 1. Alexithymia Items' correlations with the total score.

\begin{tabular}{|c|c|c|c|c|}
\hline Item & & Correlation Item & & Correlation \\
\hline 1 & $.458^{* *}$ & 15 & $.570^{* *}$ & \\
\hline 2 & $.539^{* *}$ & 16 & $.457^{* *}$ & \\
\hline 3 & $.576^{* *}$ & 17 & $.394^{* *}$ & \\
\hline 4 & $.591^{* *}$ & 18 & $.484^{* *}$ & \\
\hline 5 & $.623^{* *}$ & 19 & $.483^{* *}$ & \\
\hline 6 & $.667^{* *}$ & 20 & $.544^{* *}$ & \\
\hline 7 & $.616^{* *}$ & 21 & $.613^{* *}$ & \\
\hline 8 & $.498^{* *}$ & 22 & $.622^{* *}$ & \\
\hline 9 & $.639^{* *}$ & 23 & $.455^{* *}$ & \\
\hline 10 & $.573^{* *}$ & 24 & $.606^{* *}$ & \\
\hline 11 & $.590^{* *}$ & 25 & $.523^{* *}$ & \\
\hline 12 & $.597^{* *}$ & 26 & $.415^{* *}$ & \\
\hline 13 & $.610^{* *}$ & 27 & $.573^{* *}$ & \\
\hline 14 & $.629^{* *}$ & 28 & $.245^{* *}$ & \\
\hline
\end{tabular}

Table 1. illustrates of Items' correlations with the total score. The maximum correlation was 0.67 , while the minimum correlation was 0.25 . These correlations were significant at $\mathrm{p}<0.01$.

The Career Decision Self-Efficacy Short Form. Career decision-making self-efficacy was measured by the 25-item Career Decision-making Self -efficacy Scale-Short Form (CDSE-SF: Betz, Klein, \& Taylor, 1996). The CDSE-SF is a 25-item short form of the original Career Decision Self-Efficacy scale. The CDSE-SF assesses five domains including self-efficacy to accomplish accurate self-appraisals, selfefficacy to select specific goals, self-efficacy to formulate plans for the future, self-efficacy to gather occupational information, and self-efficacy to engage in effective problem solving.

Validity

Face validity was assessed by submitting the scale to a panel of experts whose specialization is counseling or psychological measurement. Construct validity was also assessed by conducting Exploratory Factor Analysis on a pilot sample $(n=60)$. Factor Analysis yielded one factor with 21 items; that is, 4 items were deleted because of low loadings, figure 2. Consequently, the final version of the AS items included 21 items, which are responded according to a 5-point Likert-type scale: (complete confidence $=5$, much confidence $=4$, moderate confidence $=3$, very little confidence $=2$ and no confidence at all $=1$ ). The total score (maximum score) obtained by summing up the scores of all items was 105, the minimum score was 21 , and the average score was 63. Any score above 63 indicates higher degree of career decision-making self-efficacy and any score at 63 indicates moderate career decision-making self-efficacy, while any score below 63 indicates lower degree of career decision-making self-efficacy.

\section{Reliability}

Reliability was expressed by Cronbach Alpha to find internal consistency for all items. The AS has demonstrated solid internal consistency (Cronbach's alpha $=0.80$ ) as shown in table 2. Table 2 illustrates Items' correlations with the total score. The maximum correlation was 0.54 , while the minimum correlation was 0.32 . These correlations were significant at $\mathrm{p}<0.01$. 
Table 2. The CDSE-SF Items' correlations with the total score.

\begin{tabular}{|c|c|c|c|c|}
\hline Item & & Correlation Item & & Correlation \\
\hline 1 & $.365^{* *}$ & 12 & $.428^{* *}$ & \\
\hline 2 & $.457 * *$ & 13 & $.317^{* *}$ & \\
\hline 3 & $.538^{* *}$ & 14 & $.373 * *$ & \\
\hline 4 & $.446^{* *}$ & 15 & $.379 * *$ & \\
\hline 5 & $.386^{* *}$ & 16 & $.369 * *$ & \\
\hline 6 & $.524^{* *}$ & 17 & $.470 * *$ & \\
\hline 7 & $.382^{* *}$ & 18 & $.397 * *$ & \\
\hline 8 & $.524^{* *}$ & 19 & $.469 * *$ & \\
\hline 9 & $.488^{* *}$ & 20 & $.527 * *$ & \\
\hline 10 & $.423^{* *}$ & 21 & $.394^{* *}$ & \\
\hline 11 & $.448^{* *}$ & & & \\
\hline
\end{tabular}

\section{Statistical tests}

Means, standard deviations, t-test, Univariate analysis and Scheffe's test were utilized to answer the study questions; that is data collected from the sample was analyzed by these test using SPSS.

\section{Results and Discussion}

Data collected from both groups was analyzed by SPSS. To answer question 1: What is the degree of alexithymia and career decision making self-efficacy (CDMSE) among Tenth and Eleventh grade students? $\mathrm{t}$-test for One-sample was used to find the significance of the difference from the mean of items $(\mathrm{M}=3)$. Table 3 illustrates findings of t-test of One- sample.

Table 3. Findings of t-test of One- sample.

\begin{tabular}{|c|c|c|c|c|c|c|c|c|}
\hline & \multirow{4}{*}{\multicolumn{2}{|c|}{ Mean $\begin{array}{r}\text { Std. } \\
\text { Deviation }\end{array}$}} & \multirow{2}{*}{\multicolumn{4}{|c|}{ Test Value $=3$}} & \multirow{3}{*}{\multicolumn{2}{|c|}{$\begin{array}{l}95 \% \text { Confidence } \\
\text { Interval of the } \\
\text { Difference }\end{array}$}} \\
\hline & & & & & & & & \\
\hline & & & \multirow[b]{2}{*}{$\mathrm{t}$} & \multirow[b]{2}{*}{$\mathrm{df}$} & \multirow[b]{2}{*}{ Sig. (2-tailed) } & \multirow{2}{*}{$\begin{array}{c}\text { Mean } \\
\text { Difference }\end{array}$} & & \\
\hline & & & & & & & Lower & Upper \\
\hline Alexithymia & 2.8864 & .75913 & $-3.530-$ & 555 & .000 & -.11364 & $-.1769-$ & -.0504 \\
\hline CDMSE & 3.8659 & .50298 & 40.592 & 555 & .000 & .86587 & .8240 & .9078 \\
\hline
\end{tabular}

Table 3 shows that the degree of alexithymia was below the mean $(M=3)$; that is, its mean was 2.89. The difference between alexithymia's mean and $(\mathrm{M}=3)$ was significant, $\mathrm{t}(1,555)=-3.530,(\mathrm{P}>0.001)$. The findings in table 3 also shows that the degree of CDMSE was above the mean $(\mathrm{M}=3)$; that is, its mean was 3.87. The difference between CDMSE's mean and $(M=3)$ was significant, $t(1,555)=40.592,(P>0.001)$.

The findings of that alexithymia is less common in the school students mean that alexithymia is classified as a psychiatric disorder with psychosomatic symptoms not as a normal problem; namely, it is more common in psychiatric or psychotherapeutic populations. Students who have or develop depressive symptoms are more liable to manifest or demonstrate alexithymic symptoms. This finding is not consistent with the results of previous studies that showed that alexithymia is common in children and adolescents (Sakkinen, Kaltiala-Heino, Ranta, Haataja, \& Joukamaa, 2007); (Cerutti, Valastro, Tarantino, Valeriani, Faedda, Spensieri and Guidetti, 2016), (Loas, Braun, Delhaye, and Linkowski, 2017) \& (Puşcaşua, and Usaci, 2016). 
In addition, the findings also indicated that students in the tenth and eleventh grades had high degree of career decision-making self-efficacy; which means that students in this developmental stage are strongly interested in planning for their career future, so they strive to develop cognitive abilities to reach their career goals and aspirations. In this crucial stage, the students attempted to improve self-exploration and career planning, so it is reasonable for the high school students to have higher career decision-making self-efficacy. This finding is in line with the results of (Ziebell,2010) study which indicated that students had greater levels of career decision making self-efficacy, and study results of (Yat Hung ,2007) which indicated that the high school students had higher expectations on career self-efficacy.

To answer question 2: Is there a significant correlational relationship between alexithymia and career decision making self-efficacy (CDMSE)? Correlation coefficient was calculated and it was found to be $(\mathrm{R}=0.049, \mathrm{P}=0.252)$. This correlation was not significant, which means that there was no significant correlational relationship between alexithymia and career decision making self-efficacy (CDMSE). It seems logical that this relationship does not exist, because when individuals have higher scores in a variable, and at the same time have lower scores in other one, it is true to say that the relationship between them is weak or does not exist. Although there were no previous studies in this context unfortunately, this gives the current study power and originality.

With respect to question 3: Are there significant effects in alexithymia due to gender, and GPA? Means and standard deviations were calculated and Univariate Analysis was conducted. Means and standard deviations are illustrated in table 4, and findings of Univariate Analysis are illustrated in table 5.

Table 4. Means and standard deviations of alexithymia scores

\begin{tabular}{ccccc}
\hline Gender & GPA & Mean & Std. Deviation & N \\
\hline \multirow{2}{*}{ Male } & accepted & 81.44 & 19.183 & 52 \\
& good & 78.14 & 19.740 & 105 \\
& v good & 77.03 & 18.258 & 87 \\
& excellent & 72.32 & 21.777 & 34 \\
& Total & 77.70 & 19.505 & 278 \\
Female & accepted & 85.54 & 23.774 & 28 \\
& good & 82.92 & 19.769 & 48 \\
& v good & 84.09 & 22.603 & 120 \\
& excellent & 83.73 & 23.710 & 82 \\
& Total & 83.93 & 22.489 & 278 \\
& accepted & 82.87 & 20.847 & 80 \\
& good & 79.64 & 19.809 & 153 \\
& v good & 81.13 & 21.130 & 207 \\
& excellent & 80.39 & 23.648 & 116 \\
& Total & 80.81 & 21.260 & 556 \\
\hline
\end{tabular}

Table 5 shows that there was no significant effect of GPA on alexithymia, $F(3,555)=0.930$, $(p=$ 0.426 , effect size $=0.005)$, while there was significant effect of gender on alexithymia, $F(1,555)=11.473$, $(\mathrm{p}=0.001$, effect size $=0.021)$, which means that there were significant gender differences in favor of females whose mean was 83.93 compared to males whose mean was 77.70 as shown in table.4. The findings also showed that there was no significant effect of the interaction of GPA * Gender on alexithymia, $\mathrm{F}(3,555)=0.587,(\mathrm{p}=0.624$, effect size $=0.003)$. 
Table 5. Univariate Analysis of the effect of gender, grade and GPA on alexithymia.

\begin{tabular}{lllllll}
\hline \multicolumn{1}{c}{ Source } & \multicolumn{1}{c}{ SS } & df & \multicolumn{1}{c}{ MS } & \multicolumn{1}{c}{ F } & P & Effect size \\
\hline Corrected Model & $9.310 \mathrm{a}$ & 7 & 1.330 & 2.347 & .023 & .029 \\
Intercept & 3618.931 & 1 & 3618.931 & 6386.565 & .000 & .921 \\
GPA & 1.581 & 3 & .527 & .930 & .426 & .005 \\
Gender & 6.501 & 1 & 6.501 & 11.473 & .001 & .021 \\
GPA * Gender & .998 & 3 & .333 & .587 & .624 & .003 \\
Error & 310.523 & 548 & .567 & & & \\
Total & 4951.910 & 556 & & & & \\
Corrected Total & 319.833 & 555 & & & & \\
\hline
\end{tabular}

These findings mean that because of the self-fulfilled prophecy related to parenting styles, girls in childhood even in adolescence are not given opportunity or freedom to express their ideas and feelings, which refers that they are often repressed or punished if they express freely. This finding about ascertaining gender differences in alexithymia is consistent with the research results of (Eastabrook, 2007), (Kaur and kaur ,2015) (Sakkinen, Kaltiala-Heino, Ranta, Haataja, \& Joukamaa ,2007) \& (Honkalampi, Tolmunen, Hintikka, Rissanen, Kylma, Laukkanen ,2009).

In regard to question 4: Are there significant effects in career decision-making self-efficacy (CDMSE) due to gender, and GPA? Means and standard deviations were calculated and Univariate Analysis was conducted. Means and standard deviations are illustrated in table 6, and findings of Univariate Analysis are illustrated in table 7.

Table 6. Means and standard deviations of CDMSE scores

\begin{tabular}{ccccc}
\hline Gender & GPA & Mean & Std. Deviation & N \\
\hline \multirow{2}{*}{ Male } & accepted & 77.6346 & 10.59417 & 52 \\
& good & 81.8000 & 10.13600 & 105 \\
& v good & 82.4483 & 9.91447 & 87 \\
& excellent & 80.2647 & 10.99396 & 34 \\
Female & Total & 81.0360 & 10.35605 & 278 \\
& accepted & 75.0000 & 12.58159 & 28 \\
& good & 77.3830 & 10.47887 & 47 \\
& v good & 82.4286 & 9.53101 & 119 \\
& excellent & 84.1205 & 10.76965 & 83 \\
& Total & 81.3285 & 10.80108 & 277 \\
& accepted & 76.7125 & 11.32064 & 80 \\
& good & 80.4342 & 10.41183 & 152 \\
& v good & 82.4369 & 9.67085 & 206 \\
& excellent & 83.0000 & 10.93003 & 555 \\
\hline
\end{tabular}


Table 7. Univariate Analysis of the effect of gender, grade and GPA on CDMSE.

\begin{tabular}{|c|c|c|c|c|c|c|}
\hline Source & SS & $\mathrm{df}$ & MS & $\mathrm{F}$ & $\mathrm{P}$ & Effect size \\
\hline \multirow[t]{2}{*}{$\begin{array}{l}\text { Corrected Model } \\
\text { Intercept }\end{array}$} & $3512.583 a$ & 7 & $\begin{array}{r}501.798 \\
2793845.141\end{array}$ & 4.700 & .000 & .057 \\
\hline & 2793845.141 & 1 & & 26165.673 & .000 & .980 \\
\hline GPA & 2378.541 & 3 & 792.847 & 7.425 & .000 & .039 \\
\hline Gender & 70.290 & 1 & 70.290 & .658 & .418 & .001 \\
\hline GPA * Gender & 1039.440 & 3 & 346.480 & 3.245 & .022 & .017 \\
\hline Error & 58406.037 & 547 & 106.775 & & & \\
\hline Total & 3719654.000 & 555 & & & & \\
\hline Corrected Total & 61918.620 & 554 & & & & \\
\hline
\end{tabular}

Table 7 shows that there was no significant effect of gender on CDMSE, $F(1,555)=0.658,(p=$ 0.418 , effect size $=0.001$ ), as well as there was no significant effect of the interaction of GPA * Gender on CDMSE, $F(3,555)=3.245,(p=0.418$, effect size $=0.001)$, while there was significant effect of GPA on CDMSE, $F(3,555)=7.425$, $(p<0.001$, effect size $=0.039)$, which means that there were significant differences in CDMSE due to GPA. To find the direction of significant differences in GPA levels, Scheffe's test was used as illustrated in table 8.

Table 8. Scheffe's test

\begin{tabular}{llll}
\hline & & Mean Difference(I-J) & \\
(J) GPA & (I) GPA & & Sig. \\
\hline good & accepted & -.1777 & .078 \\
v good & & $-.2726\left(^{*}\right)$ & .001 \\
excellent & & $-.2994\left(^{*}\right)$ & .001 \\
accepted & good & .1777 & .078 \\
v good & & -.0949 & .353 \\
excellent & & -.1217 & .256 \\
accepted & vgood & $.2726\left(^{*}\right)$ & .001 \\
good & & .0949 & .353 \\
excellent & & -.0268 & .974 \\
accepted & excellent & $.2994\left(^{*}\right)$ & .001 \\
good & & .1217 & .256 \\
v good & & .0268 & .974 \\
\hline
\end{tabular}

Table 8 shows that there were significant differences between accepted level and both very good, and excellent in favor of very good and excellent.

These findings mean that males and females in high schools receive the same career counseling services and resources, as well as they have the same developmental characteristics because of minor age differences. These services often focus on developing and improving self-awareness, self-exploration and self-planning in students. This implies that providing career counseling programs for students in high schools help them to make career choice, which results in developing their abilities to plan their career future in the long run. This finding is consistent with the research results of (Betz and Hackett ,1986), (Wan Lai Yin ,2013), \& (Yat Hung ,2007) which showed significant gender differences in career decision making self-efficacy, but this finding didn't go along with the research results of (Lozano,2015). (Bergeron \& Romano, 1994; Bright, 1996; Wilson, 2000), (Ziebell, 2010). 


\section{Conclusion}

The study concludes that although there was no significant correlational relationship between alexithymia and career decision-making self-efficacy, alexithymia negatively affects individual's decisions in life. Because alexithymic individual has externally -oriented thinking, it is reasonable to imply that he/she will make decision based on external factors, such as people ideas and conceptions. Family, school and community are more influential on the decisions of individual with alexithymia. Alexithymia has received a great deal of interest by the researchers in many European states. They conducted different research study on diverse categories of children and adolescents. From our viewpoint, alexithymia is strongly related to cultural factors, namely, there are cultural differences in expressing and understanding feelings between Arab populations and European ones that is the latter are more open to feelings compared to Arab people who have suppression in feeling expression. In addition, career decision -making self-efficacy has also received a great deal of interest in European studies, that is the problems of career decision making paid the researchers' attention to seek for the best counseling solutions by using the most effective strategies to improve career decision making in students of secondary schools (Gymnasiums). This study included some implications related to counseling specifically career counseling. Other implications may be viable to psychology, psychiatry and psychosomatics.

\section{References}

Bagby, R. M., Parker, J. D. A., \& Taylor, G. J. (1994). The twenty-item Toronto Alexithymia Scale-1. Item selection and cross-validation of the factor structure. Journal of Psychosomatic Research, 38, 23-32.

Bandura, A. (1977) Self-efficacy: Toward a unifying theory of behavioral change. Psychological Review, 84, 191-215.

Bandura, A. (1982). Self-efficacy mechanism in human agency. American Psychologist, 37(2), 122-147.

Bandura, A. (1986). Social foundations of thought and action: A social cognitive theory. Englewood Cliffs, NJ: Prentice Hall.

Bandura, A. (2001). Social cognitive theory: An agentic perspective. Annual Review Psychology, 52, 1-26

Bandura, A. (2009). Exercise of personal and collective efficacy in changing societies. In Albert

Bandura (Ed.). Self-efficacy in Changing Societies. Cambridge: Cambridge University Press, pp.1-45.

Bergeron, L. M., \& Romano, J. L. (1994). The relationships among career decision-making self-efficacy, educational indecision, vocational indecision, and gender. Journal of College Student Development, 35, 19-24.

Betz, N. E., \& Hackett, G. (1986). Applications of self-efficacy to understanding career choice behavior. Journal of Social and Clinical Psychology, 4, 279-289.

Betz, N. E., Klein, K., \& Taylor, K. M. (1996). Evaluation of a short form of the Career Decision-Making Self-Efficacy scale. Journal of Career Assessment, 4, 47-57.

Bright, J. L. (1996). Gender and role salience in the prediction of undergraduates' career decision-making self-efficacy. (Doctoral dissertation). Retrieved from ProQuest Dissertations and Theses. (UMI 9705679).

Cecchetto, C., Korb, S. Ida Rumiati, R. and Aiello, M. (2017). Emotional reactions in moral decisionmaking are influenced by empathy and alexithymia. Social Neuroscience, DOI: 10.1080/17470919.2017.1288656.

Cerutti, R. Valastro, C. Tarantino, S. Valeriani, M. Faedda, N. Spensieri, V. and Guidetti, V. (2016). Alexithymia and psychopathological symptoms in adolescent outpatients and mothers suffering from migraines: a case control study. The Journal of Headache and Pain, 17(39), DOI 10.1186/s10194-0160640-y.

Dahl, R.E. (2003). The development of affect regulation: bringing together basic and clinical perspectives. Annals of the New York Academy of Sciences, 1008, 183-188. [PubMed: 14998884].

De Vente, W., Kamphuis, J., \& Emmelkamp, P. (2006). Alexithymia, risk factor or consequence of workrelated stress? Psychotherapy and Psychosomatics, 75(5), 304-311.

Eastabrook, J.M. (2007). Assessment of adolescent alexithymia: Examining the ability of the TAS -20 to measure alexithymia in samples of community and clinical adolescents. (Thesis). Retrieved from ProQuest Dissertations, Theses- Library, and Archives Canada. 
Honkalampi, K., Hintikka, J., Tanskanen, A., Lehtonen, J., \& Viinamäki, H. (2000). Depression is strongly associated with alexithymia in the general population. Journal of Psychosomatic Research, 48(1), 99-104.

Hackett, G., \& Lent, R. W. (1992). Theoretical advances and current inquiry in career psychology. In S. D. Brown \& R. W. Lent (Eds.), Handbook of Counseling Psychology (2nd Ed., pp. 419-452). New York: Wiley.

Hendryx, M.S, Haviland M.G, and Shaw, D.G. (1991). Dimensions of alexithymia and their relationship to anxiety and depression. Journal of Personality Assessment, 6,227-237.

Honkalampi, K., Tolmunen, T., Hintikka, J., Rissanen, M.L., Kylma, J., and Laukkanen, E. (2009). The prevalence of alexithymia and its relationship with Youth Self-Report problem scales among Finnish adolescents. Comprehensive Psychiatry, 50, 263-268.

Kaur, H. and Kaur, S. (2015). Social Anxiety in Relation to Alexithymia among Adolescents. Journal of Psychosocial Research, 10(2), 421-429.

Lent, R. W., \& Hackett, G. (1987). Career self-efficacy: Empirical status and future directions [Monograph]. Journal of Vocational Behavior, 30,347-382.

Lent, R.W., Brown, S.D., \& Hackett, G. (1994). Toward a unifying social cognitive Theory of career and academic interest, choice, and performance. Journal of Vocational Behavior, 45, 79-122.

Lent, R.W. \& Brown, S.D. (2013a). Understanding and facilitating career development in the 21st century. In R.W. Lent \& S.D. Brown (Eds.), Career development in counseling: putting theory and research to work (pp. 1-26). Hoboken, NJ: Wiley.

Lent, R.W. \& Brown, S.D. (2013b). Social cognitive model of career self-management: Toward a unifying view of adaptive career behavior across the life, span. Journal of Counseling Psychology, 60. 557-568. DOI: $10.1037 / a 0033446$.

Ioana, A., \& Puşcaşu, D. U. (2015). The impact of alexithymia on interpersonal relationships in adolescence. Romanian Journal of Romanian Applied Psychology, 7(1), 321-325.

Loas, G.A., Braun, S. Delhaye, M. and Linkowski, P. (2017). The measurement of alexithymia in children and adolescents: Psychometric properties of the Alexithymia Questionnaire for Children and the twenty-item Toronto Alexithymia Scale in different non-clinical and clinical samples of children and adolescents. PLOS ONE 12(5): e0177982.https: / / doi.org/10.1371/journal.pone.0177982.

Lozano, M.M. (2015). The effects of the connect to success academy on high school student's achievement motivation. (Doctoral dissertation). Retrieved from ProQuest Dissertations and Theses. (UMI 3712631).

Lumley, M. A., Neely, L. C., \& Burger, A. J. (2007). The Assessment of Alexithymia in Medical Settings: Implications for Understanding and Treating Health Problems. Journal of Personality Assessment, 89(3), 230-246.

Matsumoto, D. (2009). The Cambridge dictionary of psychology. Cambridge: Cambridge University Press.

Mayer, J.D, Salovey, P., Caruso, D.R, and Sitarenios G. (2001). Emotional intelligence as a standard intelligence. Emotion, 1,232-242. [PubMed: 12934682].

Puşcaşua, A.I. and Usaci, P.D. (2016). The Impact of alexithymia on interpersonal relationships in adolescence. Romanian Journal of Experimental Applied Psychology, 7(1), 321-325.

Sadock, B.J. and Sadock, V.A. (2000). Kaplan \& Sadock's Comprehensive Textbook of Psychiatry. New York: Lippincott Williams \& Wilkins Publishers.

Sakkinen, P., Kaltiala-Heino, R., Ranta, K., Haataja, R., and Joukamaa, M. (2007). Psychometric properties of the 20- item Toronto Alexithymia Scale and prevalence of alexithymia in a Finnish adolescent population. Journal of Psychosomatic research, 48, 154-161.

Taylor, G.J., (1984). Alexithymia: concept, measurement, and implications for treatment. American Journal of Psychiatry 141, 725-732.

Taylor, G.J., (1987). Alexithymia: culture and class relationships: A symposium. Transcultural Psychiatric Research Review, 4, 85-95.

Taylor, G.J., (2000). Recent developments in alexithymia theory and research. Canadian Journal of Psychiatry 45, 134-142.

Taylor, G. J., Bagby, R., \& Parker, J. (1997). Disorders of affect regulation: Alexithymia in medical and psychiatric illness. New York, NY US: Cambridge University Press.

Taylor, G.J, Ryan, D., and Bagby, R, M. (1985). Toward the development of a new self-report alexithymia scale. Psychotherapy and Psychosomatics, 44, 191- 199.

The relationship between alexithymia and career decision -making self-efficacy among Tenth and Eleventh ... 57 Indonesian Counselor Association (IKI) | DOI: https://doi.org/10.23916/0020190420520 
Taylor, K. M, \& Betz, N. E. (1983). Applications of self-efficacy theory to the understanding and treatment of career indecision. Journal of Vocational Behavior, 22, 63-81.

Taylor, G. J., Parker, J. A., Bagby, R., \& Bourke, M. P. (1996). Relationships between alexithymia and psychological characteristics associated with eating disorders. Journal of Psychosomatic Research, 41(6), 561-568.

Vorst, H. C. M., \& Bermond, B. (2001). Validity and reliability of the Bermond-Vorst Alexithymia Questionnaire. Personality and Individual Differences, 30, 413-434.

Wan Lai Yin, W. (2013). Roles of parental influences, personality and career decision-making self-efficacy in predicting vocational interests and choice goals among Hong Kong secondary school students. (Doctoral dissertation). Retrieved from ProQuest Dissertations and Theses. (UMI 3578888).

Warnes, H., (1986). Alexithymia, clinical and therapeutic aspects. Psychotherapy and Psychosomatics 46, 96-104.

Wilson, L. M. (2000). The relationship between parental attachment, career decision-making self-efficacy, gender, race and career indecision. (Doctoral dissertation). Retrieved from ProQuest Dissertations and Theses. (UMI 9973260).

Yat Hung, C. (2007). Career decision-making self-efficacy and outcome expectations in secondary student school-towork transition. (Doctoral dissertation). Retrieved from ProQuest Dissertations and Theses. (UMI 3302426).

Zackheim, L. (2007). Alexithymia: the expanding realm of research. Journal of Psychosomatic Research, 63(4), 345-347.

Ziebell, J.L. (2010). Promoting Viable Career Choice Goals through Career Decision-Making Self-Efficacy and Career Maturity in Inner-City High School Students: A Test of Social Cognitive Career Theory. (Doctoral dissertation). Retrieved from ProQuest Dissertations and Theses. (UMI 3422537). 